\title{
Effect of current density and behaviour of second phases in anodizing of a Mg-Zn-RE alloy in a fluoride/glycerol/water electrolyte
}

\author{
A. Němcová ${ }^{1}$ - I. Kuběna ${ }^{2}$ • M. Šmíd ${ }^{3}$ • H. Habazaki ${ }^{4}$ - P. Skeldon ${ }^{1}$ • G. E. Thompson ${ }^{1}$
}

Received: 16 February 2015 /Revised: 11 April 2015 / Accepted: 17 April 2015 / Published online: 1 May 2015

(C) The Author(s) 2015. This article is published with open access at Springerlink.com

\begin{abstract}
Anodizing of a Mg-Zn-RE alloy was carried out at constant current densities from 0.1 to $10 \mathrm{~mA} \mathrm{~cm}^{-2}$ in a fluoride/glycerol/water electrolyte. Rutherford backscattering spectroscopy, nuclear reaction analysis and analytical transmission electron microscopy revealed barrier-type films composed of oxide and fluoride species. The films were formed by outward migration of cations and inward migration of anions. The transport number of cations in the film above the matrix was in the range $\sim 0.5$ to 0.6 , and $\sim 0.1$ in the film above the grain boundary Mg-Zn-RE phase. From the oxidation behaviour of the $\mathrm{Zn}-\mathrm{Zr}$ phases, it is suggested that anions and cations migrate through short-circuit paths in the film.
\end{abstract}

Keywords Magnesium · Anodizing · Anodic film · TEM · RBS

\section{Introduction}

The use of magnesium alloys is potentially attractive for many applications owing to their light weight. However, surface treatment is often required in order to provide the requisite corrosion protection. Electrolytic processes, such as anodizing

P. Skeldon

p.skeldon@manchester.ac.uk

1 Corrosion and Protection Group, School of Materials, The University of Manchester, Manchester M13 9PL, UK

2 CEITEC IPM, Žižkova 22, Brno 616 62, Czech Republic

3 Institute of Physics of Materials, AS CR, Žižkova 22, Brno 616 62, Czech Republic

4 Division of Materials Chemistry, Faculty of Engineering, Hokkaido University, Sapporo, Hokkaido 060-8628, Japan and plasma electrolytic oxidation, are commonly employed, and a variety of processes is available that produce relatively thick, porous coatings under dielectric breakdown [1-5], which are usually used as part of a coating system. The coatings are also of interest for biodegradable magnesium implants, enabling control of the corrosion rate and enhancing the biocompatibility [6, 7]. Films formed in the absence of dielectric breakdown are also being investigated. Fluorinerich, nanoporous and nanotubular films have been produced using an ethylene glycol/hydrofluoric acid electrolyte [8], as well as thick porous films, containing magnesium, oxygen and carbon species, using ethanol or methanol electrolytes containing nitrate ions [9]. In contrast, barrier films, containing organic and phosphate species, have been grown in amine/ ethylene glycol and hot phosphate/glycerol electrolytes, respectively $[10,11]$, and low-voltage films that contain electrolyte components have been formed in an ionic fluid [12]. Other work has employed a variety of aqueous electrolytes, revealing films containing $\mathrm{Mg}(\mathrm{OH})_{2}$ [13], $\mathrm{MgF}_{2}$ and $\mathrm{Mg}_{\mathrm{x}+\mathrm{y} /}$ ${ }_{2} \mathrm{O}_{\mathrm{x}}(\mathrm{OH})_{\mathrm{y}}[14], \mathrm{MgO}$ and $\mathrm{MgAl}_{2} \mathrm{O}_{4}[15,16]$ hydroxide or oxyhydroxide [17] and $\mathrm{MgF}_{2}$ [18].

Despite the significant research into the anodizing of magnesium, the understanding of the film growth mechanisms is much less developed in comparison with other metals, such as aluminium and tantalum. Mechanistic investigations of film growth are made easier when the films are of uniform thickness and relatively unreactive in the electrolyte. Such films have recently been formed using a fluoride/glycol/water electrolyte [19]. The films were nanocrystalline and grew by outward migration of cations and inward migration of anions, with a formation ratio of $\sim 1.24 \mathrm{~nm} \mathrm{~V}^{-1}$. Further, a study of a Mg-Zn-RE alloy, using a fluoride/glycerol/water electrolyte, revealed similar films, but with the thickness differing between the matrix and the second phase within the alloy [20]. The films were rich in fluoride species, with diffraction 
revealing $\mathrm{MgF}_{2}$ and also $\mathrm{MgO}$. Both studies used a central band of film material that contained an enhanced amount of oxygen and a reduced amount of fluorine as a marker to assess the contributions of anion and cation migration to film formation. The band was derived from the oxide/hydroxide film that was present on the alloy surface before anodizing commenced. The position of the band indicated a transport number of cations in the range $\sim 0.5$ to 0.6 for the films on the sputtering deposited magnesium and at the matrix regions of the alloy. The cation transport number is large compared with other examples of nanocrystalline anodic films. For example, the cation transport numbers for nanocrystalline anodic oxide films formed on hafnium and zirconium, which are the best known examples, are $\leq 0.05[21,22]$.

In the present study, the effect of current density on the formation of the films on a cast Mg-Zn-RE alloy is investigated, contrasting with the single current density used in the previous studies [19, 20]. Further, the oxidation of $\mathrm{Zn}-\mathrm{Zr}$ phases of the alloy is examined in order to shed light on ionic migration in the film.

\section{Experimental}

A Mg-Zn-RE magnesium was supplied by Magnesium Elektron Ltd as a cast slab of $2.5 \mathrm{~cm}$ thickness. The composition of the alloy in $\mathrm{wt} \%$ according to inductively coupled plasma optical emission spectroscopy was $3.2 \% \mathrm{Nd}, 0.8 \%$ $\mathrm{Zr}, 0.7 \% \mathrm{Zn}, 0.2 \% \mathrm{Gd}$, bal. $\mathrm{Mg}$. The slab was cut to provide specimens with dimensions of $2.5 \times 2.0 \times 0.5 \mathrm{~cm}$. One face of each specimen, of dimensions $2.5 \times 2.0 \mathrm{~cm}$, was then wet ground, using deionized water, on successive grades of silicon carbide paper to a 4000-grit finish. After grinding, the specimens were cleaned ultrasonically in acetone and dried in a flow of cool air. The specimens were then anodized in a Perspex cell at constant current densities of $0.1,1,5,7$ and $10 \mathrm{~mA} \mathrm{~cm}{ }^{-2}$ using a glycerol-based electrolyte containing $0.35 \mathrm{M}$ ammonium fluoride and $5 \mathrm{vol} . \%$ of added water at $293 \mathrm{~K}$. The anodizing was carried out up to voltages close to the dielectric breakdown voltages in order to maximize the film thickness. Each specimen was clamped against a port in the cell, where an O-ring provided a seal with the specimen surface. The working area of the specimen was $1.54 \mathrm{~cm}^{2}$. The cathode was a platinum wire. The current was supplied by a constant current source (Metronix Model 6912). The cell voltage during anodizing was recorded using in-house software based on Labview. After anodizing, the specimen was rinsed in deionized water and dried as previously.

The examination of specimens was concentrated on those formed at $0.1,5$ and $10 \mathrm{~mA} \mathrm{~cm}^{-2}$. Scanning electron microscopy (SEM) was used for investigation of the alloy microstructure and the surfaces of the anodic films, employing Zeiss EVO 50 and Zeiss Ultra 55 instruments operated at 15 and
$3 \mathrm{kV}$, respectively. Cross-sections of anodized specimens were prepared for transmission electron microscopy (TEM) using a TESCAN Lyra 3 XMU equipped with a focused ion beam (FIB) milling facility. Specimens were coated with platinum to prevent irradiation damage during preparation. The FIB was operated at an accelerating voltage of $30 \mathrm{kV}$, with currents of 4 and $1 \mathrm{nA}$ for rough milling and rough pre-thinning, respectively. An ion current of $200 \mathrm{pA}$ was used for final thinning to an electron-transparent thickness. At the end of the preparation procedure, all TEM sections were cleaned by an ion beam, using an accelerating voltage of $2 \mathrm{kV}$ and current of $150 \mathrm{pA}$, in order to minimize the ion irradiation damage. This procedure has been described in detail elsewhere [23]. TEM investigations were performed using a JEOL $2100 \mathrm{~F}$ instrument operated at $200 \mathrm{kV}$ and equipped with an Oxford instruments X-max energy-dispersive X-ray (EDX) analysis facility. Elemental distributions in sections were measured in the STEM mode with Aztec software.

The compositions of anodic films were investigated by Rutherford backscattering spectroscopy (RBS) employing $2 \mathrm{MeV}^{4} \mathrm{He}^{+}$ions supplied by the van de Graff generator at the University of Namur, Belgium. The incident ion beam was normal to the specimen surface, with scattered ions detected at $165^{\circ}$ to the direction of the incident beam. The data were interpreted using SIMNRA software. The carbon, oxygen and fluorine contents of specimens were assessed by nuclear reaction analysis (NRA) using the ${ }^{12} \mathrm{C}\left(\mathrm{d}, \mathrm{p}_{0}\right){ }^{13} \mathrm{C},{ }^{16} \mathrm{O}\left(\mathrm{d}, \mathrm{p}_{1}\right){ }^{17} \mathrm{O}$ and ${ }^{19} \mathrm{~F}\left(\mathrm{~d}, \mathrm{p}_{11,12}\right)^{20} \mathrm{~F}$ reactions, employing $0.87 \mathrm{MeV}^{2} \mathrm{H}^{+}$ions, with detection of emitted protons at $150^{\circ}$ to the direction of the incident beam. The oxygen contents were quantified using a reference specimen of anodized tantalum and were corrected for the isotopic abundance of ${ }^{16} \mathrm{O}$. Details of the analysis of ${ }^{16} \mathrm{O}$ by NRA can be found elsewhere [24]. The carbon content was estimated from the ratio of the yields of the ${ }^{12} \mathrm{C}\left(\mathrm{d}, \mathrm{p}_{0}\right){ }^{13} \mathrm{C}$ and ${ }^{16} \mathrm{O}\left(\mathrm{d}, \mathrm{p}_{1}\right)^{17} \mathrm{O}$ reactions, using literature values of the respective cross-sections [25]. Fluorine could not be quantified by NRA, due to lack of data on the reaction cross-sections.

\section{Results}

\section{Alloy microstructure}

The microstructure in a mechanically polished section of the alloy is shown in the scanning electron micrograph of Fig. 1. The backscattered electron image reveals light regions where heavier elements, i.e. rare earth metals, zinc and zirconium, are located. The discontinuous Mg-Zn-RE phase occurs at grain boundaries, with lengths up to tens of microns and widths of up to $\sim 10 \mu \mathrm{m}$; EDX analyses by SEM and TEM revealed a composition of about $\mathrm{Mg}-6$ at. $\% \mathrm{Zn}-10$ at. $\% \mathrm{Nd}$, corresponding to a $(\mathrm{Mg}+\mathrm{Zn}) / \mathrm{Nd}$ atomic ratio of $\sim 9$ and a $\mathrm{Mg} / \mathrm{Nd}$ ratio of $\sim 12$, the latter suggesting a phase based on 


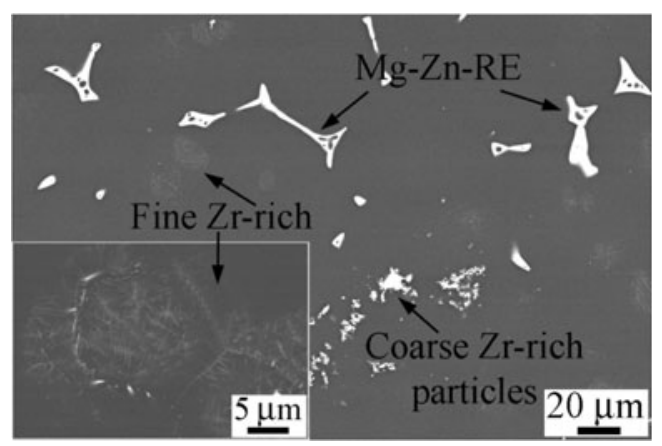

Fig. 1 Scanning electron micrograph (backscattered electrons) of the microstructure of the $\mathrm{Mg}-\mathrm{Zn}-\mathrm{RE}$ alloy

$\mathrm{Mg}_{12} \mathrm{Nd}$. Clusters of sub-micron sized, zirconium-rich particles are evident within grain centres, occupying regions of up to $\sim 20 \mu \mathrm{m}$ in size. Coarser, zirconium-rich particles also occur, which were less common than other second phase particles.

\section{Voltage-time behaviour}

At the start of anodizing, a voltage surge occurred due to the resistance of the electrolyte. The voltage then increased at a constant rate, as typical of the formation of a barrier-type anodic film. The dependence of the rate on the current density is shown in Fig. 2. Table 1 gives the voltage increments associated with film growth, i.e. the differences between the surge and final anodizing voltages that were employed in this work. The increments were the maximum that could be achieved without the occurrence of gas evolution and sparking due to dielectric breakdown.

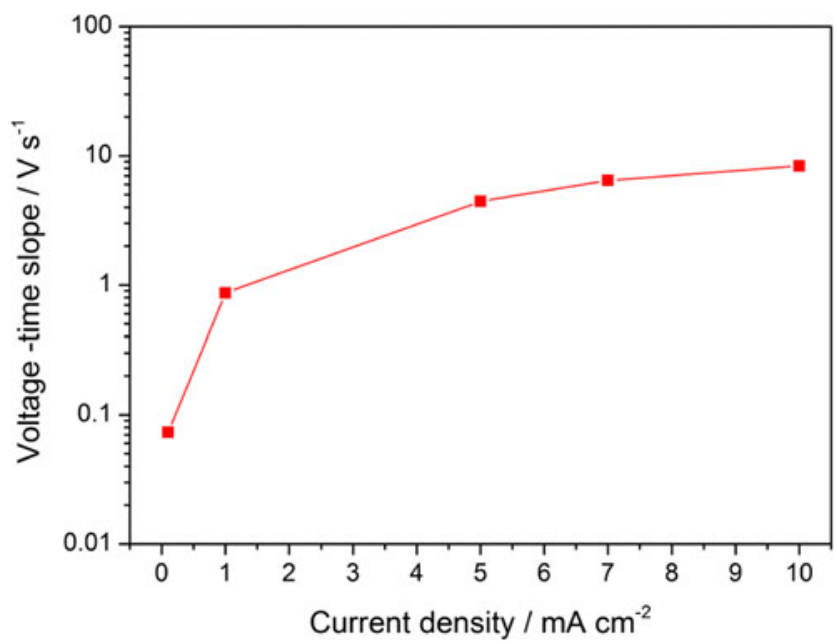

Fig. 2 The relationship between the gradient of the voltage-time response and the current density for anodizing $\mathrm{Mg}-\mathrm{Zn}-\mathrm{RE}$ alloy in a glycerol-based electrolyte containing $0.35 \mathrm{M}$ ammonium fluoride and 5 vol. $\%$ of added water at $293 \mathrm{~K}$

\section{Scanning electron microscopy of the alloy surface before and after anodizing}

Figure 3 presents secondary electron scanning electron micrographs of the surface of the alloy after pre-treatment by grinding and also after subsequent anodizing. Figure 3 a shows the ground surface at a matrix region, revealing grooves and a network of light features due to cracks in a thin oxide/ hydroxide film that was formed during grinding of the alloy. The surfaces of the anodic films were similar at all current densities. Hence, images are shown only for the film formed at $10 \mathrm{~mA} \mathrm{~cm}$. Figure $3 \mathrm{~b}$ shows the film formed above regions of the alloy matrix and the Mg-Zn-RE phase. The film on the Mg-Zn-RE phase protrudes above the film on the matrix. The matrix film is comparatively smooth, whereas that on the Mg-Zn-RE phase reveals grooves, which are associated with the alloy pre-treatment. The retention of grooves on the $\mathrm{Mg}-\mathrm{Zn}-\mathrm{RE}$ phase is probably due to the formation of the anodic film in such regions mainly by inward transport of anion species, whereas at the matrix, a much greater contribution to film growth is made by the outward transport of cations [20]. Hence, more film material is formed at the film surface above the matrix regions than above the $\mathrm{Mg}-\mathrm{Zn}-\mathrm{RE}$ phase, which enables greater smoothing of the surface. The matrix region of the image also shows some small regions of raised film formed above fine second phase particles. Fig. $3 \mathrm{c}$ shows a region where a greater population of fine second phase particles is present. The raised film regions commonly appeared as isolated nodules of a few tens of nanometres in size, or as linear features, of up to $\sim 1 \mu \mathrm{m}$ in length, each formed from a row of nodules. Small pores are often associated with nodules. The nodules probably arise from the early stages of dielectric breakdown that occur preferentially in the film formed above the second phase particles. The further stages of dielectric breakdown probably generated the two large protrusions of film material, which were zirconium-rich. Such features were present on the anodized surfaces at low population densities that did not significantly affect later ion beam analyses of films.

\section{Transmission electron microscopy of the film formed at $0.1 \mathrm{~mA} \mathrm{~cm}^{-2}$}

Figure 4a shows a bright field transmission electron micrograph of the film formed at $0.1 \mathrm{~mA} \mathrm{~cm}$ to $401 \mathrm{~V}$ above the alloy matrix. The film displays a central light band, located at depths in the range $0.47-0.52$ of the film thickness, which has been attributed to the incorporation of the oxide/hydroxide film formed on the alloy before the start of anodizing [20]. The film material above the band has a finely textured appearance, which contrasts with the more featureless underlying material. The EDX elemental linescans of Fig. 4b-g show that magnesium, neodymium, fluorine and oxygen are present 
Table 1 Results of RBS and NRA analyses of the anodic films formed on the Mg-Zn-RE alloy following anodizing at different current densities in a glycerol-based electrolyte containing $0.35 \mathrm{M}$ ammonium fluoride and 5 vol. $\%$ of added water at $293 \mathrm{~K}$

\begin{tabular}{|c|c|c|c|c|c|c|c|c|c|}
\hline $\begin{array}{l}\text { Current density } \\
\left.(\mathrm{mA} \mathrm{cm})^{-2}\right)\end{array}$ & $\begin{array}{l}\text { Voltage increments } \\
\text { (V) }\end{array}$ & $\begin{array}{l}\mathrm{Mg} \\
\left(\times 10^{15}\right.\end{array}$ & $\begin{array}{l}\mathrm{F} \\
\text { atoms cm }\end{array}$ & O (NRA) & $\mathrm{RE}$ & RE enrichment & Zn enrichment & Ratio $\mathrm{O} / \mathrm{F}$ & $\begin{array}{l}\text { Efficiency } \\
(\%)\end{array}$ \\
\hline 0.1 & 401 & 1660 & 3000 & 362 & 10.4 & 1.2 & $\leq 0.5$ & 0.12 & $94 \pm 10$ \\
\hline 1 & 435 & 1640 & 2750 & 551 & 10.7 & 1.6 & 1.5 & 0.20 & $98 \pm 5$ \\
\hline 5 & 434 & 1520 & 2590 & 585 & 9.7 & 1.8 & 2.1 & 0.23 & $104 \pm 6$ \\
\hline 10 & 416 & 1450 & 2480 & 608 & 9.6 & 2.2 & 3.3 & 0.25 & $103 \pm 6$ \\
\hline
\end{tabular}

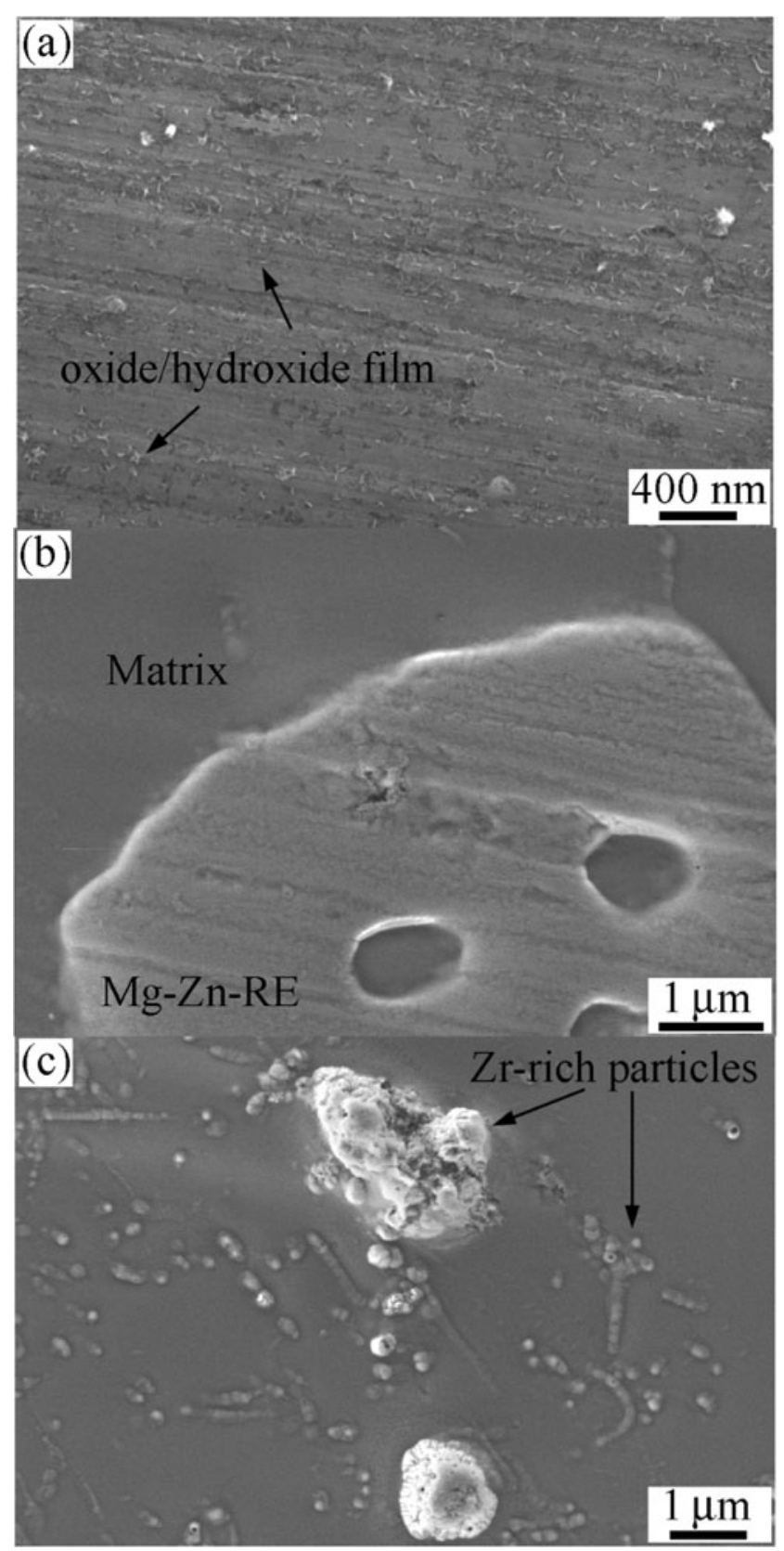

Fig. 3 Scanning electron micrographs (secondary electrons) of a the ground surface of the $\mathrm{Mg}-\mathrm{Zn}-\mathrm{RE}$ alloy and $\mathbf{b}$, $\mathbf{c}$ following anodizing to $416 \mathrm{~V}$ at $10 \mathrm{~mA} \mathrm{~cm}^{-2}$ in a glycerol-based electrolyte containing $0.35 \mathrm{M}$ ammonium fluoride and $5 \mathrm{vol} . \%$ of added water at $293 \mathrm{~K}$ throughout the film thickness, whilst carbon is concentrated in the light band near the middle of the film. Zinc is present mainly in the inner half of the film and is enriched at the alloy/film interface. No results are presented for zirconium, which could not be resolved by EDX analysis owing to its relatively low concentration.

Figure 5 shows a bright field image and EDX elemental maps of the film formed at $0.1 \mathrm{~mA} \mathrm{~cm}{ }^{-2}$ above a region of $\mathrm{Mg}-\mathrm{Zn}$-RE phase. The second phase and the overlying anodic film appear darker than the film and substrate at the matrix region due mainly to the presence of increased concentrations of heavier elements. The film is thicker above the Mg-Zn-RE phase than above the matrix and contains a light band at a depth of $\sim 0.08-0.12$ of the film thickness. The band bends toward the light band in the film above the matrix near the edge of the second phase, as marked by the arrows, indicating its similar origin. The volume changes on conversion of the metal into film material and the electric field strengths in the film material differ for the film material formed above the second phase and matrix regions. Hence, the light band within the film is displaced between the two regions.

A thinner light band is also present near the centre of the film formed above the second phase. The band lies at the boundary between an outer region of the film, where both fluorine and oxygen are present, and an inner region, which is fluorine-rich and oxygen-depleted. The distribution of oxygen suggests that it is immobile or migrates more slowly than fluorine. Relatively fast migration of fluorine species has been reported for barrier-type anodic films formed on tantalum and titanium [26, 27]. Neodymium and zinc are distributed throughout the thickness of the film, and zinc is enriched at the alloy/film interface. The EDX linescans of Fig. 6 reveal that the outer light band of Fig. 5 is enriched in oxygen and depleted in fluorine. The linescans also suggest that zinc is present at a higher concentration in the inner region of the film. The enrichment of zinc is evident near the alloy/film interface. The Mg-Zn-RE phase immediately beneath the anodic film in the micrograph of Fig. 5 shows the presence of a slightly lighter band below the zinc-enriched layer. However, there were no changes in elemental concentrations in the linescans of Fig. 6, suggesting that it may be an artefact of the FIB milling. 

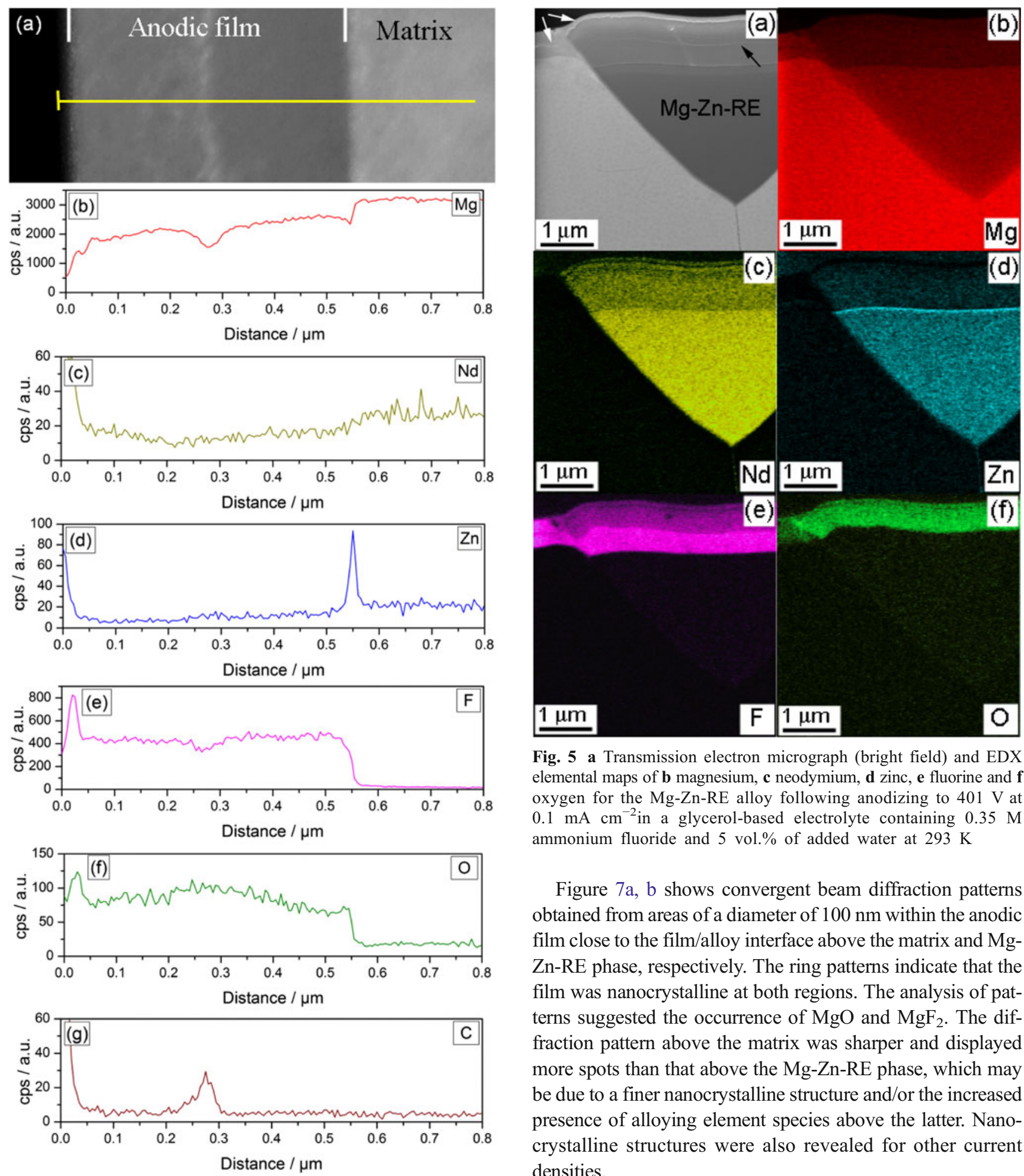

Fig. 4 a Transmission electron micrograph (bright field) of the anodic film formed above the matrix of the $\mathrm{Mg}-\mathrm{Zn}-\mathrm{RE}$ alloy following anodizing to $401 \mathrm{~V}$ at $0.1 \mathrm{~mA} \mathrm{~cm}^{-2}$ in a glycerol-based electrolyte containing $0.35 \mathrm{M}$ ammonium fluoride and 5 vol. $\%$ of added water at $293 \mathrm{~K}$. b-f Results of EDX elemental line scan analysis of $\mathbf{b}$ magnesium, $\mathbf{c}$ neodymium, $\mathbf{d}$ zinc, e fluorine, $\mathbf{f}$ oxygen and $\mathbf{g}$ carbon

Fig. 5 a Transmission electron micrograph (bright field) and EDX elemental maps of $\mathbf{b}$ magnesium, $\mathbf{c}$ neodymium, $\mathbf{d}$ zinc, $\mathbf{e}$ fluorine and $\mathbf{f}$ oxygen for the Mg-Zn-RE alloy following anodizing to $401 \mathrm{~V}$ at $0.1 \mathrm{~mA} \mathrm{~cm}{ }^{-2}$ in a glycerol-based electrolyte containing $0.35 \mathrm{M}$ ammonium fluoride and 5 vol.\% of added water at $293 \mathrm{~K}$

Figure $7 \mathrm{a}, \mathrm{b}$ shows convergent beam diffraction patterns obtained from areas of a diameter of $100 \mathrm{~nm}$ within the anodic film close to the film/alloy interface above the matrix and $\mathrm{Mg}$ $\mathrm{Zn}-\mathrm{RE}$ phase, respectively. The ring patterns indicate that the film was nanocrystalline at both regions. The analysis of patterns suggested the occurrence of $\mathrm{MgO}$ and $\mathrm{MgF}_{2}$. The diffraction pattern above the matrix was sharper and displayed more spots than that above the Mg-Zn-RE phase, which may be due to a finer nanocrystalline structure and/or the increased presence of alloying element species above the latter. Nanocrystalline structures were also revealed for other current densities.

\section{Transmission electron microscopy of the film formed at $5 \mathrm{~mA} \mathrm{~cm}^{-2}$}

Figure 8 shows a transmission electron micrograph and EDX elemental maps at the boundary between the matrix and the $\mathrm{Mg}-\mathrm{Zn}$-RE phase of a specimen anodized at $5 \mathrm{~mA} \mathrm{~cm}{ }^{-2}$ to 

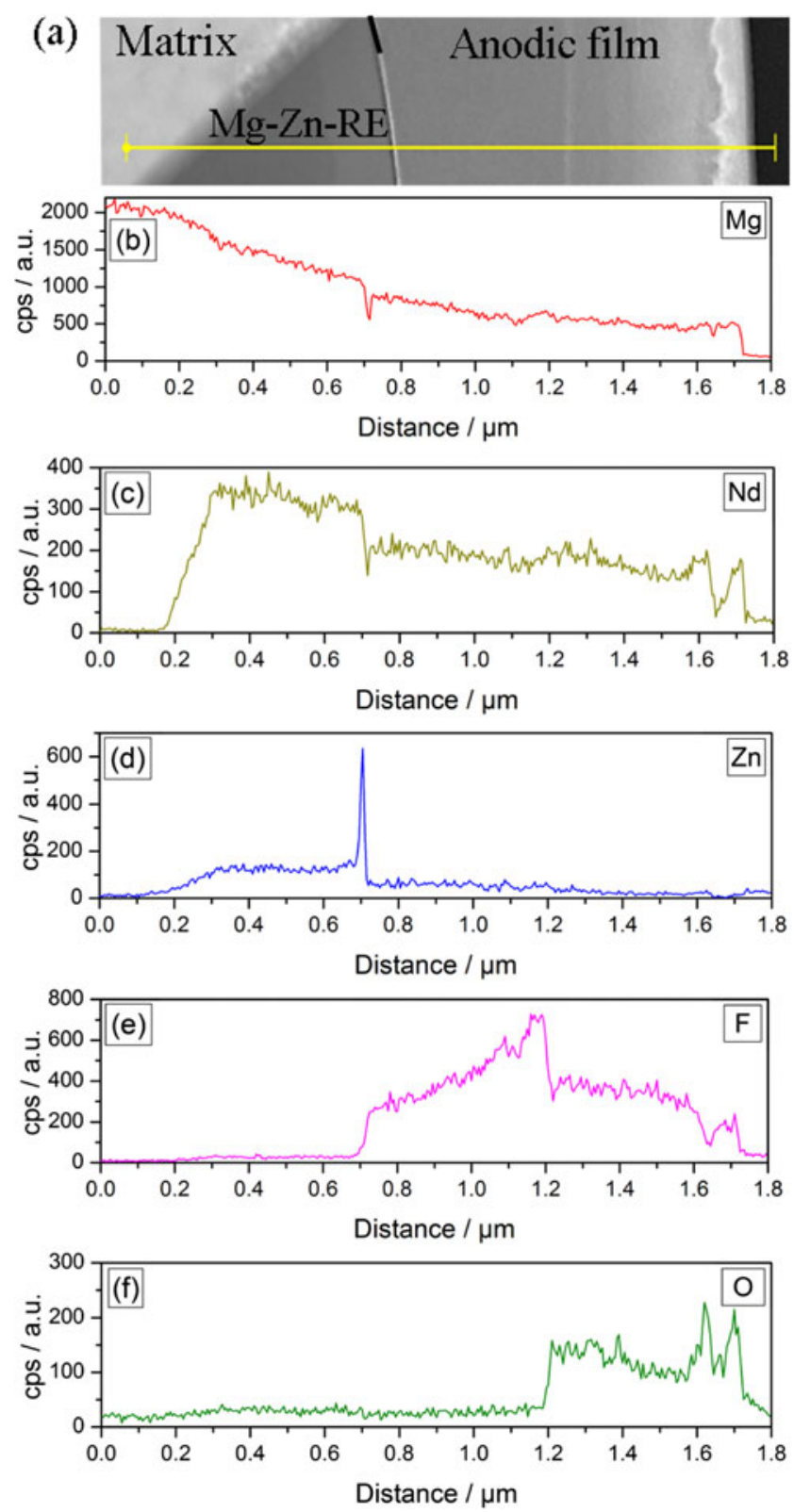

Fig. 6 Results of EDX elemental line scan analysis of the film formed above the Mg-Zn-RE phase of the Mg-Zn-RE alloy following anodizing to $401 \mathrm{~V}$ at $0.1 \mathrm{~mA} \mathrm{~cm}^{-2}$ in a glycerol-based electrolyte containing $0.35 \mathrm{M}$ ammonium fluoride and $5 \mathrm{vol} . \%$ of added water at $293 \mathrm{~K}$. a Location of line scan, $\mathbf{b}$ magnesium, $\mathbf{c}$ neodymium, $\mathbf{d}$ zinc, $\mathbf{e}$ fluorine and $\mathbf{f}$ oxygen

$434 \mathrm{~V}$. The film above the matrix resembles that formed at $0.1 \mathrm{~mA} \mathrm{~cm}{ }^{-2}$. A light band is located at $0.10-0.14$ of the thickness of the film above the Mg-Zn-RE phase, similarly to that observed in the film formed at $0.1 \mathrm{~mA} \mathrm{~cm}{ }^{-2}$. The EDX elemental maps of Fig. 8b-f reveal the presence of magnesium, zinc, neodymium, oxygen and fluorine in the film. The maps suggested an enrichment of fluorine relative to oxygen in the inner third of the anodic film on the Mg-Zn-RE phase. An enrichment of zinc at the alloy/film interface can be seen at both the second phase and matrix regions.
Figure 9 shows a bright field image of the matrix where two needle-like particles have been partly oxidized. EDX point analysis of these particles and also of the plate-like particles evident in alloy revealed relatively high concentrations of zinc and zirconium and low concentrations of neodymium, with the phases containing more zirconium than zinc. The particles possibly consist of the $\mathrm{Zr}_{2} \mathrm{Zn}_{3}$ phase [28]. The plate-like particles in the alloy had smaller particles, enriched in neodymium, around their edges. The zinc- and zirconiumrich regions within the inner half of the anodic film that have resulted from the oxidation of the needle-like particles are colinear with the non-oxidized parts of the particles. However, in the outer part of the film, they are orientated toward the film surface. The EDX elemental maps for oxygen and fluorine (not shown) disclosed negligible variations in intensity across the film thickness other than the depletion of fluorine and enrichment of oxygen in the light band.

\section{Transmission electron microscopy of the film formed at $10 \mathrm{~mA} \mathrm{~cm}{ }^{-2}$}

The anodic film formed to $416 \mathrm{~V}$ at $10 \mathrm{~mA} \mathrm{~cm}{ }^{-2}$ revealed features similar to those seen at 0.1 and $5 \mathrm{~mA} \mathrm{~cm}^{-2}$. However, the light band in the film was buried slightly deeper within the film, at $0.52-0.59$ of the film thickness. The band at the Mg$\mathrm{Zn}$-RE phase was located at a depth of $\sim 0.09-0.13$ of the film thickness, similar to the previous location. Enrichment of zinc occurred beneath the film at both the matrix and Mg-Zn-RE regions. Figure 10 shows plate-like zinc- and zirconium-rich particles being incorporated into the anodic film above the matrix. The oxidation of the particle that is circled in Fig. 10 resulted in zinc- and zirconium-rich material in the inner part of the film that is aligned with particles in the alloy matrix. However, the zinc- and zirconium-rich film material is orientated toward the film surface in the outer region of the film. The light band is also located closer to the film surface.

\section{Ion beam analysis}

Figure 11 shows the experimental and simulated RBS spectra for the specimens anodized at $0.1,5$ and $10 \mathrm{~mA} \mathrm{~cm}^{-2}$. The energies for scattering from oxygen, fluorine, magnesium, zinc, zirconium and rare earth at the film surface are indicated in the figure. Table 1 gives the results for the film compositions determined from the fitting of the experimental spectra, which also include a specimen anodized at $1 \mathrm{~mA} \mathrm{~cm}{ }^{-2}$. The total amounts of elements in the film are presented, together with the amount of RE in the RE-enriched surface region. The oxygen contents of the films were determined from NRA, since the signal from oxygen in the RBS spectra was relatively low and overlapped partly with the signal from fluorine. The results of Table 1 show that the atomic ratio of $\mathrm{O} / \mathrm{F}$ increases with increase of the current density. The ratios are $0.12,0.20$, 
Fig. 7 Electron diffraction patterns of the film formed on the $\mathrm{Mg}-\mathrm{Zn}-\mathrm{RE}$ alloy following anodizing to $401 \mathrm{~V}$ at $0.1 \mathrm{~mA} \mathrm{~cm}^{-2}$ in a glycerol-based electrolyte containing $0.35 \mathrm{M}$ ammonium fluoride and 5 vol.\% of added water at $293 \mathrm{~K}$ above a the matrix and $\mathbf{b}$ the $\mathrm{Mg}-\mathrm{Zn}-\mathrm{RE}$ phase

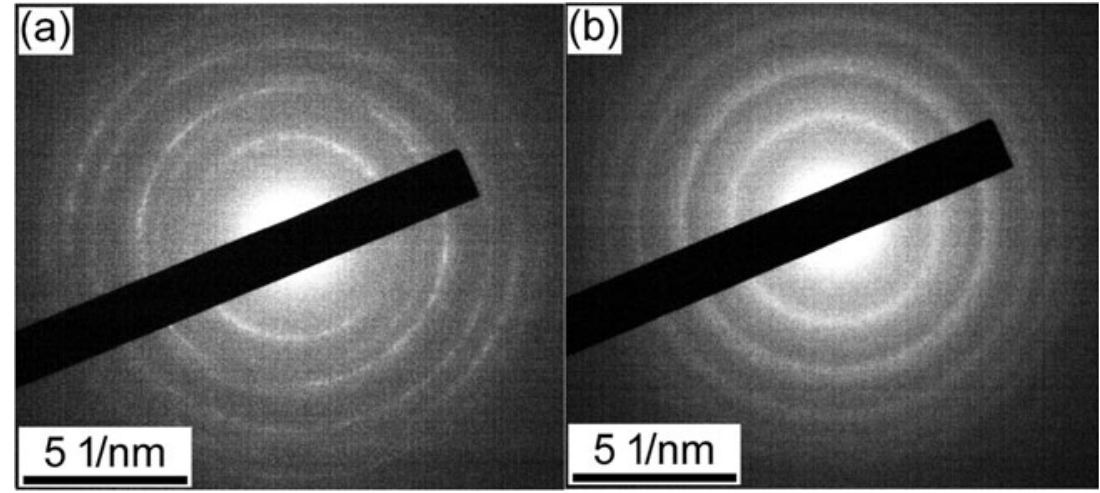

0.23 and 0.25 for current densities of $0.1,1,5$ and $10 \mathrm{~mA} \mathrm{~cm}^{-2}$, respectively. The oxygen in the film is presumed to be derived mainly from water in the electrolyte, which has been reported to be the main source of oxygen for films formed on zirconium in a similar electrolyte [29]. The molar ratio of water molecules to fluoride ions in the electrolyte is

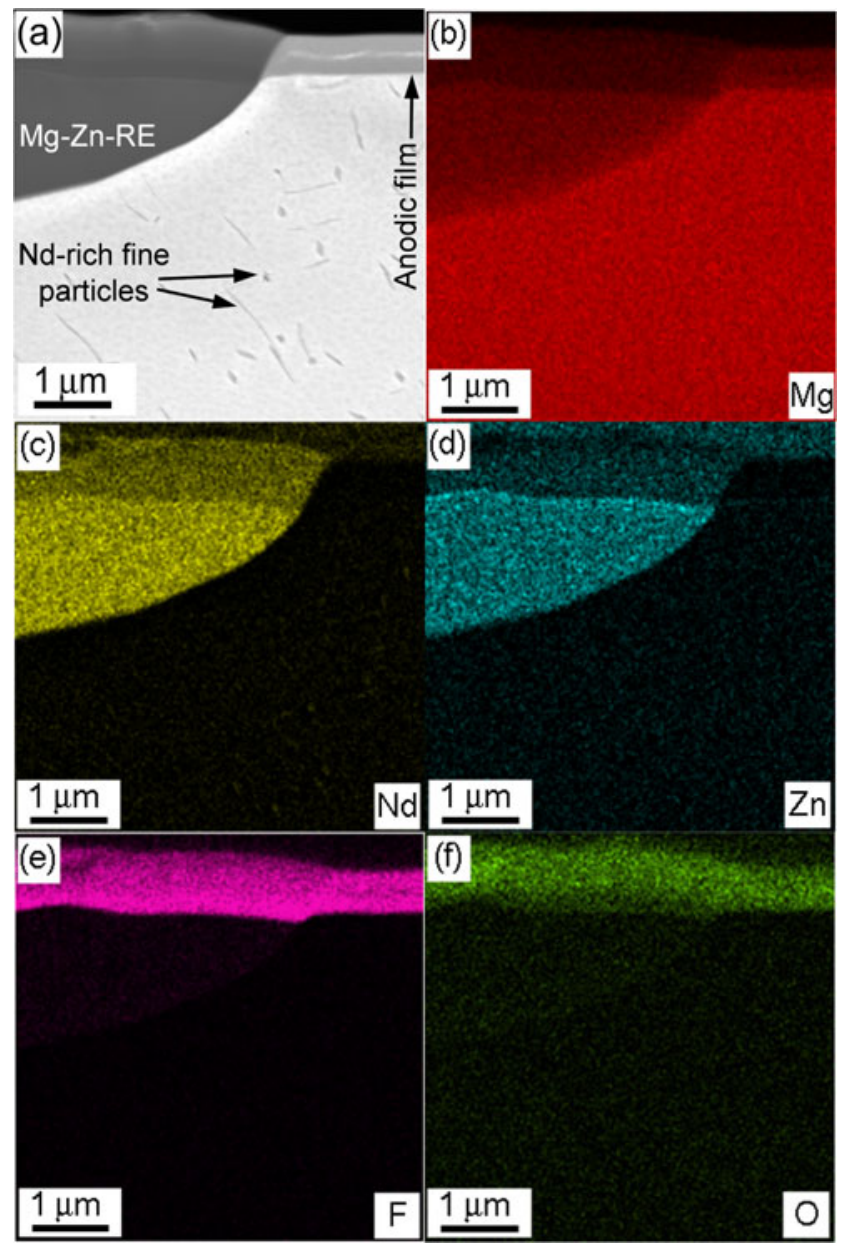

Fig. 8 a Transmission electron micrograph (bright field) and EDX elemental maps of $\mathbf{b}$ magnesium, $\mathbf{c}$ neodymium, $\mathbf{d}$ zinc, $\mathbf{e}$ fluorine and $\mathbf{f}$ oxygen for the Mg-Zn-RE alloy following anodizing to $434 \mathrm{~V}$ at $5 \mathrm{~mA} \mathrm{~cm}^{-2}$ in a glycerol-based electrolyte containing $0.35 \mathrm{M}$ ammonium fluoride and 5 vol. $\%$ of added water at $293 \mathrm{~K}$ $\sim 7.8$, which is much greater than the atomic ratio of $\mathrm{O} / \mathrm{F}$ in the films. Thus, the fluoride ions are preferentially incorporated into the film. The preferential incorporation of fluoride ions is possibly related to the more negative Gibbs free energy of formation of $\mathrm{MgF}_{2}\left(-1071.1 \mathrm{~kJ} \mathrm{~mol}^{-1}\right)$ compared with that of $\mathrm{MgO}\left(-569.3 \mathrm{~kJ} \mathrm{~mol}^{-1}\right)$. Fluoride ions may also be preferentially adsorbed on the film surface under the influence of the electric field.

The enrichment of rare earth elements at the surface region of the films increased from $1.2 \times 10^{15}$ to $2.2 \times$ $10^{15}$ neodymium atoms $\mathrm{cm}^{-2}$ between current densities 0.1 to $10 \mathrm{~mA} \mathrm{~cm}{ }^{-2}$. The amounts of other alloying elements in the film were less certain owing to their smaller yields, which were superimposed on much higher yields from the rare earths in the inner film and in the alloy. Since these elements were present in relatively low concentrations, they are not considered further. The enrichment of zinc at the alloy/film interface increased with increase in the current density, from $\leq 0.5 \times$ $10^{15}$ zinc atoms $\mathrm{cm}^{-2}$ at $0.1 \mathrm{~mA} \mathrm{~cm}^{-2}$ to $\sim 3.3 \times$ $10^{15}$ zinc atoms $\mathrm{cm}^{-2}$. These enrichments apply to the matrix regions of the alloy. The zinc enrichment at the $\mathrm{Mg}-\mathrm{Zn}-\mathrm{RE}$ phase is located at a greater depth than that at the matrix, since the film is thicker above the former region, but is not resolved by RBS as the phase occupies a small part of the analysed area.

Figure 12 shows the yields from the ${ }^{16} \mathrm{O}\left(\mathrm{d}, \mathrm{p}_{1}\right){ }^{17} \mathrm{O}$ and ${ }^{19} \mathrm{~F}\left(\mathrm{~d}, \mathrm{p}_{11,12}\right){ }^{20} \mathrm{~F}$ reactions for the previous specimens. The yields from the reactions are consistent with the findings from $\mathrm{RBS}$ that the $\mathrm{O} / \mathrm{F}$ ratio increases with increase of the current density. Yields from the ${ }^{12} \mathrm{C}\left(\mathrm{d}, \mathrm{p}_{0}\right){ }^{13} \mathrm{C}$ reaction (not shown) revealed $\sim 1 \times 10^{16}$ carbon atoms $\mathrm{cm}^{-2}$ on the ground alloy and $\sim 2 \times 10^{16}$ carbon atoms $\mathrm{cm}^{-2}$ following anodizing, irrespective of the current density. The carbon on the ground alloy is due to contamination, and similar contamination is likely on the surface of the anodic films. Further, carbon is incorporated into the light bands evident in the transmission electron micrographs [20]. Thus, carbon incorporated into the growing film from glycerol molecules appears to be $\leq 1 \times$ $10^{16}$ carbon atoms $\mathrm{cm}^{-2}$, which is negligible compared with oxygen and fluorine species. 


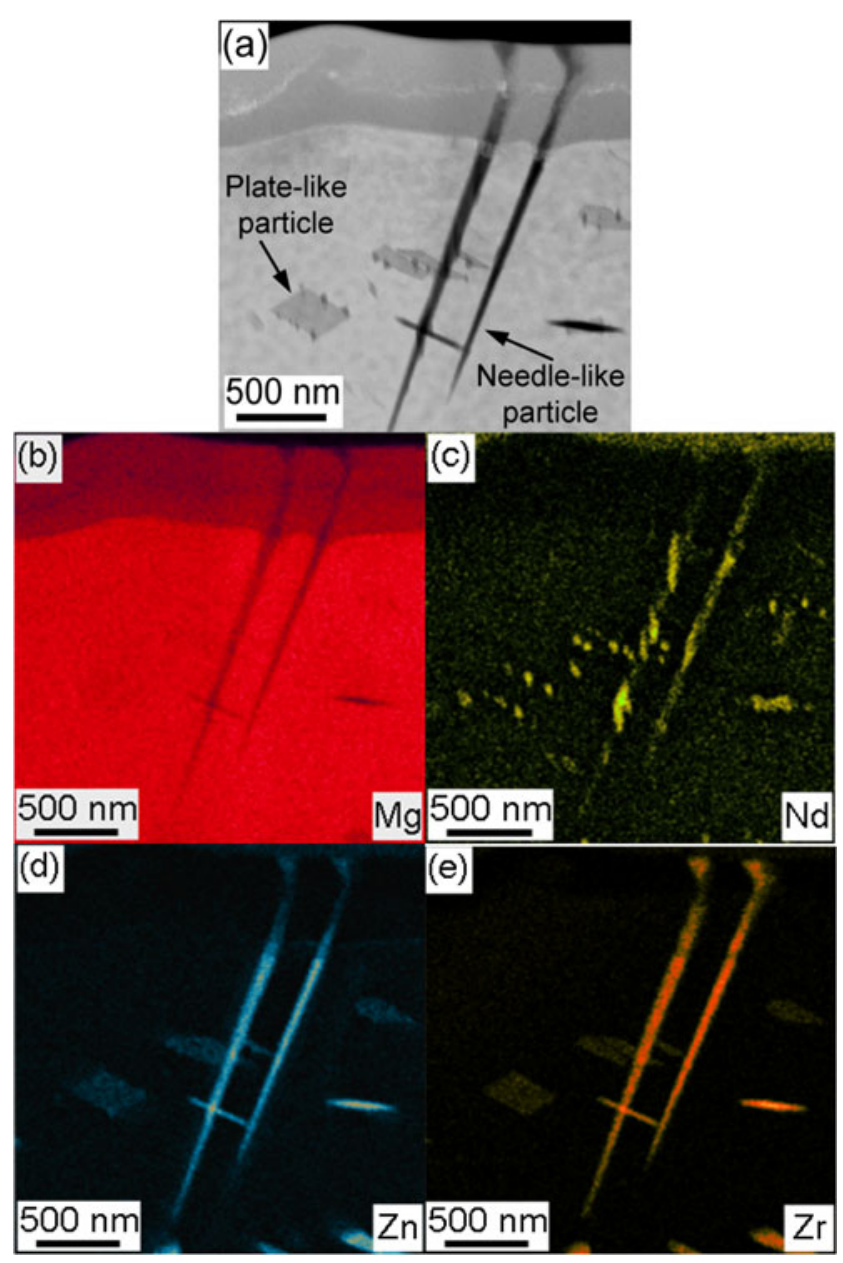

Fig. 9 a Transmission electron micrograph (bright field) and EDX elemental maps of $\mathbf{b}$ magnesium, $\mathbf{c}$ neodymium, $\mathbf{d}$ zinc and $\mathbf{e}$ zirconium for the $\mathrm{Mg}-\mathrm{Zn}-\mathrm{RE}$ alloy following anodizing to $434 \mathrm{~V}$ at $5 \mathrm{~mA} \mathrm{~cm}{ }^{-2}$ in a glycerol-based electrolyte containing $0.35 \mathrm{M}$ ammonium fluoride and 5 vol. $\%$ of added water at $293 \mathrm{~K}$

The efficiency of anodizing was calculated from the ratio of the charges due to the cations in the films and the charge passed through the cell to anodize the specimens. The charge states of magnesium and RE are assumed to be +2 and +3 , respectively. Other alloying elements were neglected due to their low and uncertain concentrations. Ratios of 0.94, 0.98, 1.04 and 1.03 were determined for current densities of $0.1,1,5$

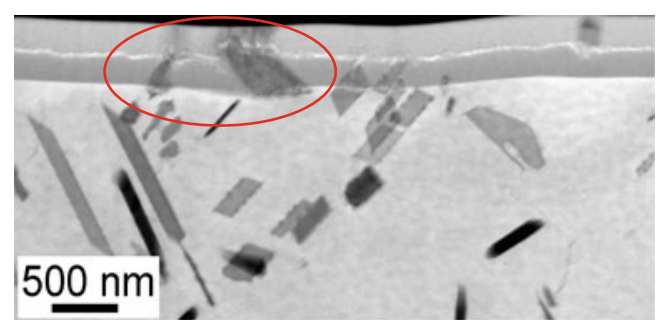

Fig. 10 Transmission electron micrograph (bright field) of the Mg-Zn$\mathrm{RE}$ alloy following anodizing to $416 \mathrm{~V}$ at $10 \mathrm{~mA} \mathrm{~cm}^{-2}$ in a glycerol-based electrolyte containing $0.35 \mathrm{M}$ ammonium fluoride and 5 vol.\% of added water at $293 \mathrm{~K}$

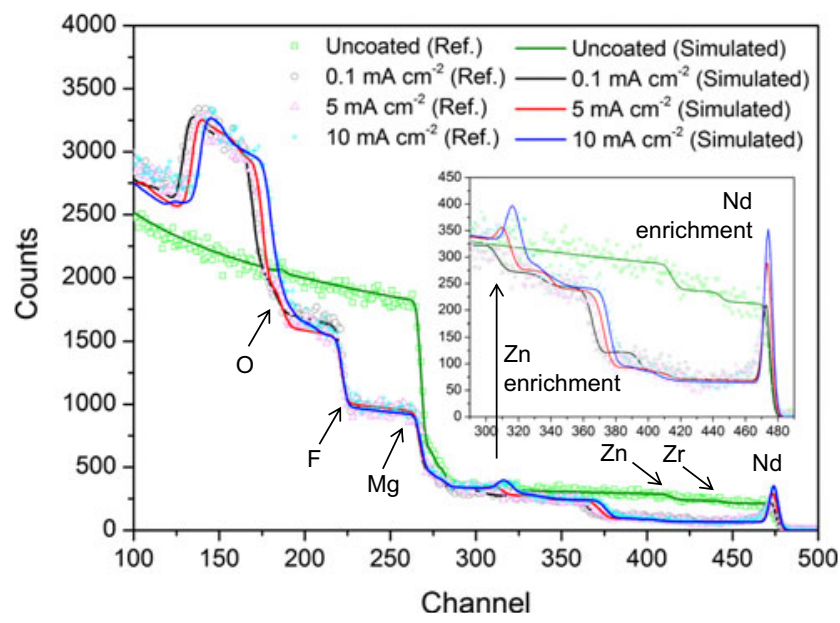

Fig. 11 Experimental and simulated (solid lines) RBS spectra for the Mg-Zn-RE alloy before anodizing and following anodizing to 401, 434 and $416 \mathrm{~V}$ at $0.1,5$ and $10 \mathrm{~mA} \mathrm{~cm}{ }^{-2}$, respectively, in a glycerol-based electrolyte containing $0.35 \mathrm{M}$ ammonium fluoride and 5 vol. $\%$ of added water at $293 \mathrm{~K}$

and $10 \mathrm{~mA} \mathrm{~cm}{ }^{-2}$, respectively (Table 1), which indicated relatively little loss of species to the electrolyte.

\section{Oxidation mechanism}

Table 2 presents the thicknesses and the formation ratios of the films at the matrix and $\mathrm{Mg}-\mathrm{Zn}-\mathrm{RE}$ regions, determined from TEM and the cell voltages of Table 1 . The Table also lists the ratio of the outer region thickness, measured to the centre of the light band, to the total thickness of each film, which represents the proportion of the film formed due to cation migration; ranges are given since the bands are slightly undulating. The formation ratios decrease with increase of current density,

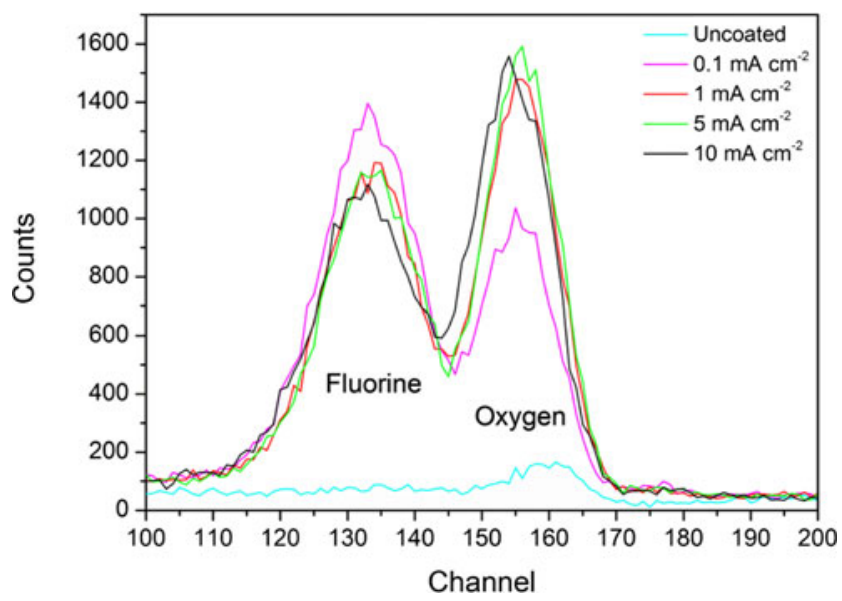

Fig. 12 Yields of the ${ }^{19} \mathrm{~F}\left(\mathrm{~d}, \mathrm{p}_{11,12}\right){ }^{20} \mathrm{~F}$ and ${ }^{16} \mathrm{O}\left(\mathrm{d}, \mathrm{p}_{1}\right){ }^{17} \mathrm{O}$ reaction $\mathrm{s}$ from NRA analyses of the Mg-Zn-RE alloy before anodizing and following anodizing to $401,435,434$ and $416 \mathrm{~V}$ at $0.1,1,5$ and $10 \mathrm{~mA} \mathrm{~cm}$, respectively, in a glycerol-based electrolyte containing $0.35 \mathrm{M}$ ammonium fluoride and 5 vol.\% of added water at $293 \mathrm{~K}$ 
Table 2 Thicknesses of film layers and formation ratios determined from transmission electron micrographs for the $\mathrm{Mg}$ Zn-RE alloy following anodizing to $401 \mathrm{~V}$ at $0.1 \mathrm{~mA} \mathrm{~cm}^{-2}$ in a glycerol-based electrolyte containing $0.35 \mathrm{M}$ ammonium fluoride and 5 vol. $\%$ of added water at $293 \mathrm{~K}$

\begin{tabular}{lllcc}
\hline $\begin{array}{l}\text { Current density } \\
\left(\mathrm{mA} \mathrm{cm}^{-2}\right)\end{array}$ & Location & Outer layer thickness/film thickness & $\begin{array}{l}\text { Film thickness } \\
(\mathrm{nm})\end{array}$ & $\begin{array}{l}\text { Formation ratio } \\
\left(\mathrm{nm} \mathrm{V}^{-1}\right)\end{array}$ \\
\hline 0.1 & Matrix & $0.47-0.52$ & 534 & 1.33 \\
& Mg-Zn-RE & $0.08-0.12$ & 1012 & 2.52 \\
5 & Matrix & $0.45-0.57$ & 523 & 1.21 \\
& Mg-Zn-RE & $0.10-0.14$ & 809 & 1.86 \\
10 & Matrix & $0.52-0.59$ & 471 & 1.13 \\
& Mg-Zn-RE & $0.09-0.13$ & 672 & 1.62 \\
\hline
\end{tabular}

from $1.33 \mathrm{~nm} \mathrm{~V}^{-1}$ at $0.1 \mathrm{~mA} \mathrm{~cm}^{-2}$ to $1.13 \mathrm{~nm} \mathrm{~V}^{-1}$ at $10 \mathrm{~mA} \mathrm{~cm}^{-2}$ for the matrix, and from 2.52 to $1.62 \mathrm{~nm} \mathrm{~V}^{-1}$ for the Mg-Zn-RE phase. Such decreases are typical of a highfield conduction process, in which the ionic current density, $J$, is dependent on the electric field, $E$, according to the relationship:

$$
J=2 N q a \nu \exp \left(-(Q-\mathrm{qa} E) / k_{\mathrm{B}} T\right)
$$

where $N$ is the concentration of mobile species, $q$ is their charge, $a$ is the jump distance, $v$ is the attempt frequency, $Q$ is the activation energy, $k_{B}$ is Boltzmann's constant and $T$ is the temperature. Figure 13 shows the dependence of the logarithm of the current density on the electric field for the matrix and $\mathrm{Mg}-\mathrm{Zn}-\mathrm{RE}$ phase. The relationships are non-linear, which is possibly due to dependence of the film composition on the current density.

Studies of crystalline anodic oxide films on zirconium have indicated that ionic transport occurs mostly by migration of oxygen species along short-circuit paths [30]. It was proposed that crystallite defects are generated by injection of $\mathrm{O}^{2-}$ ion into the oxide at the oxide/electrolyte interface. These then

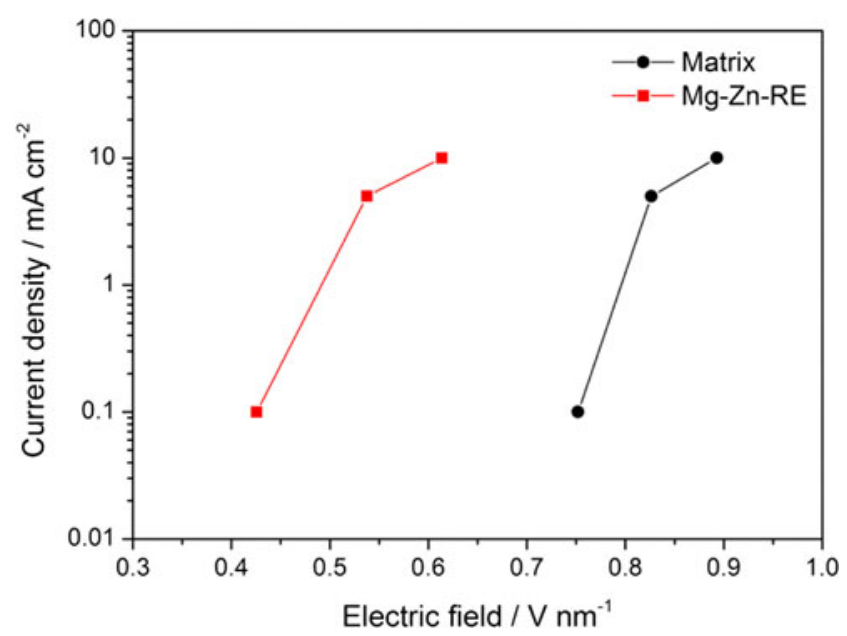

Fig. 13 Relationship between the logarithm of the current density and the electric field for anodizing of the Mg-Zn-RE alloy in a glycerol-based electrolyte containing $0.35 \mathrm{M}$ ammonium fluoride and 5 vol.\% of added water at $293 \mathrm{~K}$ propagate across the crystallites, creating a low population density of transport paths of relatively high ionic conductivity. It is suggested that ionic migration in the present films also occurs by short-circuit paths. Oxygen and fluorine species migrate to the alloy/film interface, where nanocrystals of oxide, fluoride and possibly oxy-fluoride are formed. The anions and cations inside the nanocrystals are possibly immobile, mirroring the behaviour of ion-implanted bromine in anodic zirconia [22]. Thus, the nanocrystals replicate the shape of the $\mathrm{Zn}-\mathrm{Zr}$ particles of Fig. 9. The migration of the cations in the inner region may occur preferentially though the zinc- and zirconium-rich film material, which is of reduced ionic resistivity. In contrast, cations within the outer region of the film migrate in the direction of the electric field and combine with fluorine and oxygen species at the film surface, causing the observed change in orientation of the zinc- and zirconium-rich material. The proposed growth of the film at a $\mathrm{Zn}-\mathrm{Zr}$ particle is shown schematically in Fig. 14. The present films differ significantly from anodic zirconia, since cations and anions have significant mobility in the films. Thus, generation by defect injection would have to provide easy paths for both types of species. Such a mechanism appears complex in preference to transport along crystallite boundary regions.

Enrichments of neodymium occur at the surfaces of the films above both the matrix and the $\mathrm{Mg}-\mathrm{Zn}-\mathrm{RE}$ phase. The enrichment indicates that neodymium species migrate outward in the film at a faster rate than other species. The enrichment reduced with reduction in the current density due to

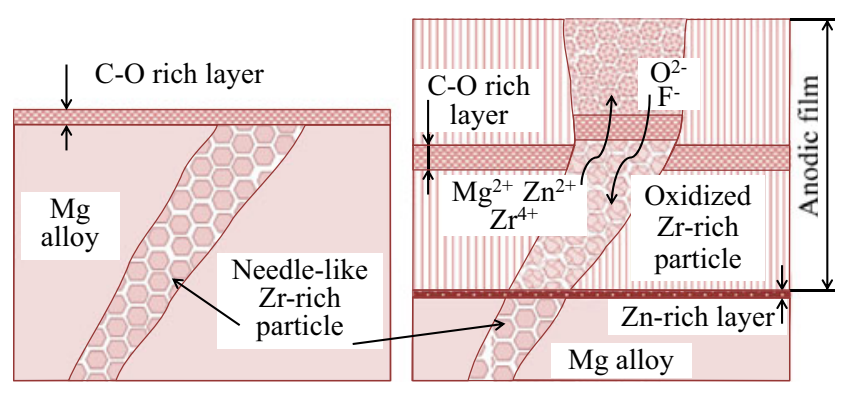

a)

b)

Fig. 14 Schematic diagram of the growth of the anodic film at the location of a $\mathrm{Zn}-\mathrm{Zr}$ second phase particle 
either a reduction in the relative migration rate of the neodymium species or an increased loss of species to the electrolyte. The latter possibility is consistent with the reduced efficiency estimated at the lowest current density. The enrichment of zinc in a thin alloy layer immediately beneath the anodic film is also found in Al-Zn alloys and has been related to the less negative Gibbs free energy per equivalent for formation of zinc oxide in comparison with that for formation of aluminium oxide [31]. However, since the present films contain greater amounts of fluorine than oxygen, the enrichment may be related to the Gibbs free energy of formation of the fluoride. The enrichment of alloying elements and the ionic transport processes in the present films require further investigations in order to develop a deeper understanding of the anodizing behaviour of fluoride-rich films on magnesium.

\section{Conclusions}

1. Anodizing of the Mg-Zn-RE alloy at a constant current density in the range 0.1 to $10 \mathrm{~mA} \mathrm{~cm}^{-2}$ in a glycerol-based electrolyte containing $0.35 \mathrm{M}$ ammonium fluoride and 5 vol.\% of added water at $293 \mathrm{~K}$ can be carried out at high Faradaic efficiency, resulting in the formation of nanocrystalline barrier-type films.

2. The anodic films contain oxygen and fluorine species, with the latter dominating the composition. The atomic ratio of $\mathrm{O} / \mathrm{F}$ increases from 0.12 to 0.25 between current densities of 0.1 and $10 \mathrm{~mA} \mathrm{~cm}^{-2}$.

3. The films form by outward migration of cation species and inward migration of anion species resulting in film growth at the alloy/film and film/electrolyte interfaces during anodizing of both the matrix and second phase regions of the alloy. The location of a band of material originating from the oxide/hydroxide film that was present on the alloy before anodizing commenced suggests that the transport number of cation species at the matrix regions lies in the range $\sim 0.5$ to 0.6 , with no significant dependence on the current density.

4. Mg-Zn-RE and Zn-Zr phases can be anodized and incorporated into the anodic films. The incorporation of the species results in local changes in the thickness of the films and the transport numbers of cation and anion species within the film.

5. Zinc is enriched in the alloy immediately beneath the film formed at regions of the matrix and $\mathrm{Mg}-\mathrm{Zn}-\mathrm{RE}$ phase. The enrichment of zinc increases with increase of the current density.

6. The oxidation behaviour of $\mathrm{Zn}-\mathrm{Zr}$ phases suggests that ionic migration proceeds along short-circuit paths in the film, such as grain boundaries or regions of less-ordered material around grain boundaries.
Acknowledgments The authors are grateful to the Engineering and Physical Sciences Research Council (UK) (LATEST2 Programme Grant) for support of this work. They also thank the European Community for financial assistance within the Integrating Activity "Support of Public and Industrial Research Using Ion Beam Technology (SPIRIT)", under EC contract no. 227012. This work was realized in CEITEC - Central European Institute of Technology - with research infrastructure supported by the project CZ.1.05/1.1.00/02.0068 financed from the European Regional Development Fund.

Open Access This article is distributed under the terms of the Creative Commons Attribution 4.0 International License (http:// creativecommons.org/licenses/by/4.0/), which permits unrestricted use, distribution, and reproduction in any medium, provided you give appropriate credit to the original author(s) and the source, provide a link to the Creative Commons license, and indicate if changes were made.

\section{References}

1. Gray JE, Luan B (2002) Protective coatings on magnesium and its alloys - a critical review. J Alloys Compd 336:88-113

2. Yerokhin AL, Shatrov A, Samsonov V, Shashkov P, Leyland A, Matthews A (2004) Fatigue properties of Keronite coatings on a magnesium alloy. Surf Coat Technol 182:78-84

3. Blawert C, Heitmann V, Dietzel W, Nykyforchyn HM, Klapkiv MD (2007) Influence of electrolyte on corrosion properties of plasma electrolytic conversion coated magnesium alloys. Surf Coat Technol 201:8709-8714

4. Hussein RO, Northwood DO, Nie X (2013) The effect of processing parameters and substrate composition on the corrosion resistance of plasma electrolytic oxidation (PEO) coated magnesium alloys. Surf Coat Technol 237:357-368

5. Mori Y, Koshi A, Liao J, Asoh H, Ono S (2014) Characteristics and corrosion resistance of plasma electrolytic oxidation coatings on AZ31B Mg alloy formed in phosphate-silicate mixture electrolytes. Corros Sci 88:254-262

6. Hornberger H, Virtanen S, Boccaccini AR (2012) Biomedical coatings on magnesium alloys - a review. Acta Biomater 8:2442-2455

7. Razavi M, Fathi M, Savabi O, Vashaee D, Tayebi L (2014) In vivo study of nanostructures akermanite/PEO coatings on biodegradable magnesium alloy for biomedical applications. J Biomed Res A. doi: 10.1002/jbm.a.35324

8. Turhan MC, Lynch RP, Jha H, Schmuki P, Virtanen S (2010) Anodic growth of self-ordered magnesium oxy-fluoride nanoporous/tubular layers on $\mathrm{Mg}$ alloy (WE43). Electochem Comm 12:796-799

9. Brunner JG, Hahn R, Kunze J, Virtanen S (2009) Porosity tailored growth of black anodic layers on magnesium in an organic electrolyte. J Electrochem Soc 156:C62-C66

10. Ono S, Asoh H (2003) Anodizing of magnesium in amine-ethylene glycol electrolyte. Mater Sci Forum 419-422:957-962

11. Yang S, Tsuji E, Aoki Y, Habazaki H (2011) Anodizing of magnesium in hot phosphate-glycerol electrolyte. 62nd ISE Annual Meeting, Toki Messe

12. Latham J-A, Howlett PC, MacFarlane DR, Somers A, Forsyth M (2012) Anodizing AZ31 in a phosphonium ionic liquid: corrosion protection through composite film dissolution. J Electrochem Soc 159:C539-C545

13. Fukada H, Matsumoto $\mathrm{Y}$ (2004) Effects of $\mathrm{Na}_{2} \mathrm{SiO}_{3}$ anodization of Mg-Al-Zn alloy in 3M KOH solution. Corros Sci 46:2135-2142

14. Ono S, Asami K, Osaka T, Masuko N (1996) Structure of anodic films formed on magnesium. J Electrochem Soc 143:L62-L63 
15. Khaselev O, Yahalom J (1998) The anodic behaviour of Mg-Al alloys in KOH-aluminate solutions. Corros Sci 40:1149-1160

16. Yahalom J, Khaselev O (1998) Constant voltage anodizing of Mg-Al alloys in $\mathrm{KOH}-\mathrm{Al}(\mathrm{OH})_{3}$ solutions. J Electrochem Soc 145:190-193

17. Bonilla F, Skeldon P, Thompson GE, Habazaki H, Shimizu K, John C, Stevens K (2002) Formation of anodic films on magnesium alloys in an alkaline phosphate electrolyte. J Electrochem Soc 149:B4-B13

18. Moon S, Nam Y (2012) Anodic oxidation of Mg-Sn alloys in alkaline solutions. Corros Sci 65:494-501

19. Habazaki H, Kataoka F, Tsuji E, Aoki Y, Nagata S, Skeldon P, Thompson GE (2014) Efficient growth of anodic films on magnesium in organic electrolytes containing fluoride and water. Electrochem Comm 46:30-32

20. Hernández-López JM, Nemcova A, Zhong XL, Liu H, Arenas MA, Haigh SJ, Burke MG, Skeldon P, Thompson GE (2014) Formation of barrier-type anodic films on Mg-Zn-RE alloy in a fluoride/ glycerol electrolyte. Electrochim Acta 138:124-131

21. Davies JA, Domeij B, Pringle JPS, Brown F (1965) The migration of metal and oxygen during anodic film formation. J Electrochem Soc 112:675-680

22. Whitton JL (1968) The measurement of ionic mobilities in anodic oxides of tantalum and zirconium by a precision sectioning technique. J Electrochem Soc 115:58-61

23. Su DH-I, Shishido HT, Tsai F, Liang L, Mercado FC (1997) A detailed procedure for reliable preparation of TEM samples using Fib milling. MRS Proc 480:105. doi:10.1557/PROC-480-105
24. Amsel G, Samuel D (1967) Microanalysis of the stable isotopes of oxygen by means of nuclear reactions. Anal Chem 39:1689-1698

25. Lennard WN, Massoumi GR, Alkemade PFA, Mitchell IV, Tong SY (1991) Revisiting the ${ }^{12} \mathrm{C}(\mathrm{d}, \mathrm{p}){ }^{13} \mathrm{C}$ reaction cross section using condensed gas targets. Nucl Instrum Meth Phys Res B: Beam Interact Mater Atoms 61:1-7

26. Shimizu K, Kobayashi K, Thompson GE, Skeldon P, Wood GC (1997) The migration of fluoride ions in growing anodic oxide films on tantalum. J Electrochem Soc 144:418-423

27. Habazaki H, Fushimi K, Shimizu K, Skeldon P, Thompson GE (2007) Fast migration of fluoride ions in growing anodic titanium oxide. Electrochem Commun 9:1222-1227

28. Wang Y-D, Wu G-H, Liu W-C, Pang S, Zhang Y, Ding W-J (2013) Influence of heat treatment on microstructures and mechanical properties of gravity cast $\mathrm{Mg}-4.2 \mathrm{Zn}-1.5 \mathrm{RE}-0.7 \mathrm{Zr}$ magnesium alloy. Trans Nonferrous Met Soc Chin 23:3611-3620

29. Muratore F, Baron-Wiechéc A, Hashimoto T, Gholinia A, Skeldon P, Thompson GE (2011) Growth of nanotubes on zirconium in glycerol/fluoride electrolytes. Electrochim Acta 56:10500-10506

30. Ortega C, Siejka J (1982) A study by nuclear microanalysis and ${ }^{18} \mathrm{O}$ tracing of the growth of anodic oxide films on zirconium. II Oxide growth mechanism. J Electrochem Soc 129:1905-1907

31. Habazaki H, Shimizu K, Skeldon P, Thompson GE, Wood GC, Zhou X (1997) Effects of alloying elements in anodizing of aluminium alloys. Trans Inst Met Finish 75:18-23 